\title{
SOBERANÍA NACIONAL \\ Y SOBERANÍAS PROVINCIALES \\ ANTE LA CORTE SUPREMA DE \\ JUSTICIA. ARGENTINA, SIGLO XIX
}

EDUARDO ZIMMERMANN

Eduardo Zimmermann es Director del Departamento

de Humanidades de la Universidad de San Andrés.

Vito Dumas y Arias, Victoria, Buenos Aires.

e-mail: zimmer@udesa.edu.ar

A poco de instaladas las nuevas instituciones de la justicia federal (Corte Suprema de Justicia de la Nación y juzgados de sección en las provincias) durante la presidencia de Bartolomé Mitre, se planteó en 1865 un caso judicial que volvería a poner en disputa las relaciones entre la Nación y las provincias, entre las fuerzas de la centralización y la descentralización política, entre concepciones de soberanía nacional y soberanías provinciales, que habían chocado una y otra vez desde la primera mitad del siglo. Esa disputa alimentaba las distintas interpretaciones que se hacían del régimen federal que, aparentemente estabilizado tras la reforma constitucional de 1860, continuaría siendo desafiado por los levantamientos provinciales a lo largo de esa década y la siguiente.

El caso planteaba una serie de incómodos interrogantes: ¿podían vecinos de una provincia demandar a la misma ante la Corte Suprema de Justicia de la Nación? ¿ No resultaba esto un avasallamiento de las instituciones provinciales y una muestra más del avance hacia la centralización del poder en las instituciones del gobierno nacional? ¿Dependía la respuesta a esa primera pregunta del grado de asimilación que el sistema constitucional argentino buscara respecto al modelo norteamericano sobre el que parecía haber sido diseñado, o se justificaba aquí un apartamiento de ese modelo?

Como señaló hace algún tiempo Carlos Garriga, la historia del derecho como disciplina estuvo estrechamente ligada, desde sus orígenes, al complejo proceso político de construcción estatal, y -al igual que la historia en general- fue un 
instrumento para la consolidación de los estados-naciones modernos. No resultó infrecuente entonces la proyección hacia el pasado de las formas estatales presentes, como una manera de naturalizar la organización política existente. Una ilustración reciente de la funcionalidad de esos mecanismos de naturalización ha sido acercada por Alejandro Agüero en su agudo análisis del desplazamiento conceptual del término «soberanía provincial» por el de «autonomía» en la historiografía y el derecho constitucional argentinos. Agüero muestra detalladamente de qué manera detrás del proceso de naturalización del segundo término, operaba una construcción política e ideológica que tendía a fortalecer la preeminencia de la soberanía nacional sobre una concepción alternativa de «soberanía dividida ${ }^{1}$.

Por otra parte, la reciente historiografía del proceso de construcción del estado nacional ha producido nuevos enfoques sobre las relaciones entre el «centro» y la «periferia» en ese proceso, y nos ha permitido revalorizar no sólo la complejidad de las relaciones establecidas entre las situaciones locales provinciales y el proceso de consolidación del estado nacional, sino también el valioso antecedente de la experiencia de la Confederación en términos de construcción institucional y formación de elencos dirigentes ${ }^{2}$.

Una cara importante de ese proceso de construcción institucional tuvo que ver con la discusión conceptual en torno a la relación entre la soberanía nacional y las soberanías provinciales, y la forma en la que esa relación se negociaría en las instituciones del nuevo estado unificado. Esa discusión conceptual se dio por un lado en las cátedras de derecho y los tratados de historia constitucional, y por otro, como veremos, en los tribunales. Algunas de esas decisiones judiciales se dieron en un contexto político fuertemente marcado por levantamientos y rebeliones que precisamente volvían a poner en tela de juicio los acuerdos institucionales

${ }^{1}$ Carlos Garriga, «Orden jurídico y poder político en el Antiguo Régimen», en el Dossier Historia y derecho, historia del derecho, en Istor. Revista de Historia Internacional, (México, CIDE), n 16, 2004, http://www.istor.cide.edu/revistaNo16.html; Alejandro Agüero, «Autonomía por soberanía provincial. Historia de un desplazamiento conceptual en el federalismo argentino (1860-1930)», Quaderni Fiorentini per la storia del pensiero giuridico moderno, 43, 2014, pp. 341-392.

2 Beatriz Bragoni y Eduardo Míguez, (coords.) Un nuevo orden político. Provincias y Estado Nacional 1852-1880, Buenos Aires, Editorial Biblos, 2010, y la bibliografía allí citada; Ana Laura Lanteri, «De lo ideal a lo posible. Dirigencia e instituciones nacionales en la Confederación (1852-1862)», Tesis doctoral, Universidad Nacional del Centro de la Provincia de Buenos Aires; Juan Carlos Garavaglia, Construir el estado, inventar la nación. El Río de la Plata, siglos XVIII-XIX, Buenos Aires, Prometeo libros, 2007. 
establecidos entre gobierno nacional y gobiernos provinciales. Tanto la Corte como los jueces federales fueron actores a través del tratamiento judicial de esos levantamientos: las rebeliones encabezadas por Aurelio Zalazar en La Rioja, en 1865; por sus seguidores en 1866, tras la derrota de Zalazar; en los movimientos que en 1866 y 1867 encabezaron Felipe Varela, Juan Saá y Juan de Dios Videla, cubriendo San Juan, Mendoza (en donde en noviembre de 1866 había estallado la Revolución de los Colorados), San Luis, La Rioja, y buena parte del Norte argentino; finalmente, en la década de 1870 la justicia federal intervino también en los levantamientos de López Jordán en Entre Ríos (1870, 1873 y 1876), y en los levantamientos mitristas en el interior tras la revolución de $1874^{3}$.

La persistencia de los conflictos por el dominio de un discurso sobre los orígenes de la nación argentina y sobre la manera de conceptualizar su organización política institucional a lo largo de la segunda mitad del siglo diecinueve ha sido explicada por los trabajos de José Carlos Chiaramonte y otros ${ }^{4}$. Sabemos gracias a los mismos que esos debates en el derecho y la historia constitucional giraban también en torno a las posibilidades de asimilar la experiencia histórica argentina al modelo norteamericano. El punto hecho por Juan Bautista Alberdi sobre la naturaleza histórica de las provincias argentinas como partes de un solo estado, que venía a justificar la mayor centralización del poder en el texto constitucional argentino al compararlo con el modelo norteamericano, sería discutido tanto por la teoría como por la historia constitucional argentina. Quienes postulaban la afinidad con el modelo norteamericano, veían a la organización nacional, y a la constitución, como un pacto entre provincias o estados preexistentes; quienes desconfiaban de

${ }^{3}$ Cf. Eduardo Zimmermann, «En tiempos de rebelión. La justicia federal frente a los levantamientos provinciales, 1860-1880», en: Bragoni y Míguez, op. cit., pp. 245-273.

4 Véanse los siguientes trabajos: José Carlos Chiaramonte, «Formas de identidad en el Río de la Plata luego de 1810», en: Boletín del Instituto de Historia Argentina y Americana «Dr. E. Ravignani», $3^{\text {a }}$ serie, $\mathrm{n}^{\circ} 1$, 1er. semestre de 1989; "El mito de los orígenes en la historiografía argentina", en: Cuadernos del Instituto Ravignani, nº 2, 1991; José Carlos Chiaramonte y Pablo Buchbinder, «Provincias, caudillos, nación y la historiografía constitucionalista argentina, 1853-1930", en: Anuario del IHES, Tandil, n VII, 1992; Pablo Buchbinder, «Emilio Ravignani: La historia, la nación y las provincias», en: Fernando Devoto (comp.), La historiografía argentina en el siglo XX (I), Buenos Aires, CEAL, 1993; Michael Riekenberg, «El concepto de la nación en la región del Plata (1810-1831)», en: Entrepasados. n 4-5, 1993; y los trabajos de Chiaramonte, Natalio Botana y Germán Bidart Campos sobre el federalismo argentino en Marcello Carmagnani (coord.), Federalismos latinoamericanos: México/ Brasil/ Argentina, México, Fondo de Cultura Económica, 1993. 
tal afinidad adherían a una visión del pasado nacional como un estado único, legado de la dominación española, y al federalismo como una concesión a las aspiraciones localistas de las provincias. Estas diferencias historiográficas se harían más notorias a partir del comienzo de la enseñanza del Derecho Constitucional en las facultades de derecho argentinas, en Córdoba desde 1858, en Buenos Aires desde 1868, cuando el modelo norteamericano comenzó a recibir mayor difusión ${ }^{5}$.

Quisiera retomar aquí estas cuestiones, con un doble propósito. En primer lugar, tomar como caso de análisis un episodio que puso nuevamente a las «soberanías provinciales» en disputa con una afirmación de la soberanía nacional y de una particular concepción del federalismo argentino, que acentuaba las tendencias centralizadoras instaladas desde el texto constitucional de 1853. En este caso, la disputa se trasladó del debate político y de la discusión en la cátedra y los tratados de derecho e historia constitucional al ámbito de la Corte Suprema de Justicia aunque, como veremos, generó también una relevante polémica doctrinaria que involucró a dos fuertes personalidades de la política y del mundo del derecho como Marcelino Ugarte y Bernardo de Irigoyen, y que se prolongaría en las décadas siguientes. Además, el caso permitió revisitar las discusiones -que también llevaban ya varios años-, sobre la validez del modelo norteamericano como guía para el ordenamiento constitucional argentino.

En segundo lugar, mi propósito será argumentar que la persistencia y fortaleza de ese clivaje «soberanía nacional/soberanías provinciales» en el debate público decimonónico argentino obstruyó la posibilidad de una discusión crítica más profunda de los fundamentos del sistema político en otra dimensión: la posibilidad de articular una crítica a la noción de soberanía que se centrara más enérgicamente en la defensa de los derechos individuales (una diferencia con la tradición del

\footnotetext{
${ }^{5}$ Sobre la enseñanza del Derecho Constitucional y estos debates véase -además de los trabajos citados en la nota anterior- algunos trabajos clásicos como Emilio Ravignani, Historia Constitucional Argentina, Buenos Aires, Peuser, 1930, cap. II; Carlos R. Melo, «Algunos antecedentes sobre la enseñanza del Derecho Constitucional en las Universidades Argentinas», en: Investigaciones y Ensayos, ${ }^{\circ}$ 6-7, enero-diciembre 1969; Roberto Etchepareborda, «Historiografía del federalismo», en: Investigaciones y Ensayos, n 14 , enero-junio 1973. Sobre el proceso de traducción de doctrina constitucional norteamericana y sus interpretaciones en el contexto argentino, Eduardo Zimmermann, «Translations of the ‘American Model) in Nineteenth Century Argentina: Constitutional Culture as a Global Legal Entanglement», en: Thomas Duve (ed.), Entanglements in Legal History: Conceptual Approaches, Global Perspectives on Legal History, I, Frankfurt, Max Planck Institute for European Legal History, 2014.
} 
modelo norteamericano que no parece haber sido señalada en los debates sobre las similitudes y diferencias entre ambos sistemas). Antes de presentar esos argumentos, es necesario analizar con algún detalle los pormenores de los argumentos jurídicos en conflicto en el caso presentado ante la Corte.

\section{LAS PROVINCIAS ANTE LA CORTE SUPREMA: EL CASO «MENDOZA Y HERMANO»}

En el año 1865, Domingo Mendoza y su hermano, comerciantes de la provincia de San Luis, se presentaron ante la Corte Suprema de Justicia de la Nación, demandando a la provincia en reclamo de una devolución de pagos hechos en virtud de una ley provincial que imponía derechos de exportación que los demandantes consideraban inconstitucional ${ }^{6}$. El caso no era muy distinto a los que se habían planteado en numerosas ocasiones en los Estados Unidos hacia fines del siglo dieciocho, cuando acreedores de los distintos estados se habían presentado ante los tribunales de la Unión para cobrar lo que les correspondía. Según sostenían los demandantes, en los Estados Unidos los estados deudores comenzaron a enarbolar la bandera de la soberanía estadual como argumento para frenar el accionar de los tribunales federales. Hasta ese momento se consideraba que las cortes federales sólo podían intervenir cuando el demandante era un estado, no un particular. Ante la acumulación de estos casos iniciados por particulares, la Corte Suprema de los Estados Unidos resolvió en 1793 en el caso Chisolm v. Georgia que los estados no tenían «inmunidad soberana» y por lo tanto las cortes federales podían entender en las causas entre estados e individuos, incluso cuando eran estos últimos quienes iniciaban las acciones ${ }^{7}$.

El problema jurídico que enfrentaban los hermanos Mendoza al sostener este argumento -que apuntaba a la asimilación del contexto argentino con los precedentes norteamericanos-, residía en que inmediatamente después del fallo de la Corte Suprema norteamericana, los reclamos en contra de esta decisión por las legislaturas estaduales se habían acumulado de tal manera que el resultado fue la

${ }^{6}$ Causa LXXII: «Domingo Mendoza y Hermano con la provincia de San Luis, sobre derechos de exportación, cuestión de competencia», Fallos de la Corte Suprema de Justicia, I, 1865, pp. 485-498, fallo del 3 de mayo de 1865; y Causa CXXXV, en Fallos de la Corte Suprema de Justicia, III, 1867, pp. 131-138, fallo del 5 de diciembre de 1865.

${ }^{7}$ Chisholm v. Georgia, 2 U.S. 419, 1793. 
Enmienda XI a la Constitución de Filadelfia. Ratificada en 1795, y con el claro propósito de anular la decisión de la Corte en Chisolm v. Georgia, la Enmienda sancionaba ahora la inmunidad soberana de cada estado contra demandas por particulares en cortes federales, estableciendo que estas últimas no estaban facultadas para entender en las causas en las que un estado era parte ${ }^{8}$.

La estrategia argumentativa para los demandantes, entonces, era clara: el marco constitucional argentino se había inspirado en los principios del modelo norteamericano; lo mismo podía decirse de buena parte de los fallos de la Corte argentina, que habían seguido de cerca a los precedentes norteamericanos ${ }^{9}$. Los principios que regulaban la cuestión planteada debían por tanto ser los mismos que habían regido en los Estados Unidos antes de la Enmienda XI, ya que ninguna mención se había hecho en la Argentina sobre la adopción de esta última norma, ni al sancionarse el texto de 1853, ni en la reforma constitucional de 1860, ni al sancionarse las leyes de organización de la justicia federal en 1863. Por lo tanto, la Corte Suprema de la Nación podía entender en la causa planteada.

Pero además de esa argumentación jurídica, los demandantes (y lo mismo harían todos los participantes en las discusiones sobre el tema), planteaban una argumentación de tipo político-institucional sobre el régimen federal argentino en apoyo de su posición:

«Que más centralizadora que la de Estados-Unidos nuestra constitución no consagra más soberanía que la del pueblo argentino; que de éste y no de las provincias emana el poder nacional, que es el único verdaderamente soberano; que esta diferencia entre las dos constituciones trae su origen de la diferente organización colonial de las dos Américas: que el sistema de Estados Unidos es una federación pura y el nuestro es una combinación que tiene por base la organización federal, pero con modificaciones requeridas por las

\footnotetext{
${ }^{8}$ Enmienda XI de la Constitución de los Estados Unidos (1795): «El poder judicial de los Estados Unidos no debe interpretarse que se extiende a cualquier litigio de derecho estricto o de equidad que se inicie o prosiga contra uno de los Estados Unidos por ciudadanos de otro Estado o por ciudadanos o súbditos de cualquier Estado extranjero».

${ }^{9}$ Sobre la manera en la que la jurisprudencia constitucional norteamericana guió a la Corte argentina en sus primeros años véase Jonathan M. Miller, «The Constitutional Authority of a Foreign Talisman: A Study of U.S. Practice as Authority in 19th Century Argentina and the Argentine Elite's Leap of Faith», The American University Law Review, 46, 5, 1997, pp. 1483-1572.
} 
tradiciones centralistas del país; que no es extraño que las Provincias Argentinas no tengan los derechos y la categoría que tienen los Estados de la Unión» ${ }^{10}$.

Para Francisco Elizalde, que representaba en la causa a la provincia de San Luis, el argumento -como era de esperarse-, era exactamente el opuesto. En primer lugar, basándose en el artículo 100 de la Constitución Nacional y el art. 1 de la Ley 48, que fijaba la competencia de la justicia federal, Elizalde sostenía que por ser los demandantes vecinos de la provincia de San Luis, no podían demandar a la provincia ante la Corte Suprema ya que las normas citadas eran claras al respecto ${ }^{11}$.

Los antecedentes norteamericanos, según los interpretaba Elizalde, también favorecían su posición: incluso antes de la Enmienda XI, la jurisprudencia había dejado establecido que la Corte Suprema era competente solamente en los casos en que un estado fuera parte demandante, y que «los derechos soberanos» de los estados impedían que éstos fueran demandados por particulares. Para reforzar su argumento, Elizalde acompañaba un buen número de citas de Hamilton, Madison, y Marshall al respecto. Habiendo sido la constitución argentina inspirada en el texto original de Filadelfia, previo a la Enmienda XI, era lógico esperar que se siguiera la misma jurisprudencia.

Pero al igual que los demandantes, además de los argumentos jurídicos Elizalde trataba de apoyar la causa de la provincia de San Luis en argumentos de tipo político sobre el régimen federal argentino: «siendo el sistema federativo la base de nuestro orden político, era necesario no olvidar que debía salvarse la indivi-

${ }^{10}$ Causa LXXII: «Domingo Mendoza y Hermano con la provincia de San Luis, sobre derechos de exportación, cuestión de competencia», Fallos de la Corte Suprema de Justicia, I, 1865, pp. 485-498.

${ }^{11}$ Art. 100, Constitución de la Nación Argentina, (1853-1860): «Corresponde a la Corte Suprema y a los tribunales inferiores de la Nación, el conocimiento y decisión de todas las causas que versen sobre puntos regidos por la Constitución, y por las leyes de la Nación, con la reserva hecha en el inc. 11 del art. 67 (hoy inc. 12 del art. 75); y por los tratados con las naciones extranjeras; de las causas concernientes a embajadores, ministros públicos y cónsules extranjeros; de las causas de almirantazgo y jurisdicción marítima; de los asuntos en que la Nación sea parte; de las causas que se susciten entre dos o más provincias; entre una provincia y los vecinos de otra; entre los vecinos de diferentes provincias; y entre una provincia o sus vecinos, contra un Estado o ciudadano extranjero». Ley 48, Organización y Competencia de la Tribunales Nacionales (1862-1863), art. 1: La Suprema Corte de Justicia Nacional conocerá en primera instancia: De las causas que versan entre dos o más Provincias, y las civiles que versen entre una Provincia y algún vecino o vecinos de otra o ciudadanos o súbditos extranjeros. 
dualidad politica de las provincias con todas sus prerrogativas en todo aquello que no hubiesen especialmente delegado en los poderes nacionales; y por consiguiente salvarse el principio constitucional que prohíbe la intervención de las autoridades nacionales en las provincias fuera de los casos expresamente determinados». Lo contrario, concluía Elizalde, implicaría establecer «una dependencia absoluta de las Provincias, aun en la soberanía no delegada».

El segundo argumento de tipo político-institucional que ensayaba Elizalde se apoyaba en el principio de división de poderes, y había sido ya discutido al sancionarse las leyes de organización de la justicia federal, al hablar de los casos en que la Nación fuera parte: debía entenderse que esa cláusula se refería a los casos en que la Nación fuera parte actora y no demandada, "pues el Poder Ejecutivo no puede ser juzgado por el Poder Judicial tan soberano como él, y la reparación de los errores que aquel cometa no deben buscarse en los Tribunales, degradando la autoridad que inviste, sino ocurriendo al Congreso, quien sin juzgar al Poder Ejecutivo, por un acto del parlamento vota una indemnización según las atribuciones que tiene de disponer de los dineros públicos».

La Corte no aceptó ninguno de los argumentos ensayados por el representante de la provincia de San Luis y en fallo del 3 de mayo de 1865 resolvió la cuestión de competencia en favor de los demandantes, reconociendo la jurisdicción federal contra la impugnación de la provincia. Los argumentos del fallo, firmado por Francisco de las Carreras, Salvador María del Carril, Francisco Delgado, y José Barros Pazos ${ }^{12}$

${ }^{12}$ Cabe recordar que esa primera conformación de la Corte Suprema no respondió a un alineamiento político con el mitrismo gobernante o con los intereses porteños. Mitre ofreció primero la presidencia de la Corte a Valentín Alsina, su rival más fuerte en Buenos Aires, que la rechazó. La presidencia sería entonces asumida por Salvador María del Carril, ex vicepresidente de la Confederación y ex gobernador de San Juan. Otros dos integrantes habían tenido actuación en Buenos Aires: Francisco de las Carreras (ex Procurador y Ministro de Hacienda de la Provincia en 1852-53, antes de la llegada de Mitre a la gobernación), y José Barros Pazos, ex ministro de Gobierno y de Relaciones Exteriores bajo Valentín Alsina. Las otras dos posiciones fueron ocupadas por Francisco Delgado (ex senador por Mendoza durante la Confederación, había sido uno de los jueces designados para la Corte Suprema de Paraná que no llegó a constituirse), y José Benjamín Gorostiaga, uno de los redactores de la Constitución de 1853 y luego Ministro del Interior de la Confederación. Véase Clodomiro Zavalía, Historia de la Corte Suprema de Justicia de la República Argentina, Buenos Aires, Peuser, 1920. Sobre la justicia federal y los alineamientos políticos en sus primeros años véase también Eduardo Zimmermann, «El Poder Judicial, la construcción del estado, y el federalismo: Argentina, 1860-1880», en: Eduardo Posada-Carbó (ed.), In Search of a New Order: Essays on the Politics of Nineteenth-Century Latin America, Londres, ILAS, 1998; y «En tiempos de rebelión. La justicia federal frente a los levantamientos provinciales, 1860-1880», en: Bragoni y Míguez, op. cit., pp. 245-273. 
apuntaban en una dirección parecida a la sostenida por los demandantes: tanto quienes redactaron el texto constitucional de 1853, como quienes participaron del proceso de reforma en 1860 conocieron la Enmienda XI a la constitución norteamericana y sin embargo no hicieron nada por incorporar sus principios al sistema constitucional argentino. Debía entenderse por lo tanto que lo que siguieron en la materia fue la jurisprudencia norteamericana establecida en Chisolm v. Georgia: las cortes federales eran competentes para entender en las causas iniciadas por particulares contra los estados o provincias. En términos más generales, la Corte sostenía que ni la independencia ni la dignidad de las provincias quedaba menoscabada por comparecer ante tribunales que también ellas habían creado para dirimir sus controversias. Y tampoco se ponía en riesgo la soberanía nacional por un potencial conflicto con los poderes provinciales:

«Que tampoco es cierto que no puedan ser las Provincias compelidas a la obediencia de los mandatos de los Tribunales de la Nación; porque disponiendo el Poder Ejecutivo, a más de los medios indirectos, el de la fuerza pública, y estando obligado a prestar su auxilio al Departamento de Justicia, no se concibe la imposibilidad del apremio, aun en el caso extremo, y que no es de suponerse por honor a los Gobiernos de Provincia, que alguno de ellos opusiese una obstinada resistencia al cumplimiento de las resoluciones que fueren contrarias a sus pretensiones» ${ }^{13}$.

Resuelta la cuestión de competencia, la Corte resolvió meses más tarde la cuestión de la restitución de los pagos hechos por Mendoza y Hermano (la ley sancionada por la Legislatura de San Luis implicaba el establecimiento de aduanas interiores, y por lo tanto se la declaraba inconstitucional), fijando que la restitución cubriría solamente los pagos hechos desde que se había iniciado la demanda ante la Corte, no los pagos anteriores realizados sin protesta. En el fallo, finalmente, la Corte contemplaba la particular situación que enfrentaban los gobiernos de provincia para solventar sus gastos, como un atenuante:

«hallándose la Nación en los primeros tiempos de su formación, y atenta a la penuria en que han quedado las Provincias con la privación de los derechos de importación

${ }^{13}$ Causa LXXII: «Domingo Mendoza y Hermano con la provincia de San Luis, sobre derechos de exportación, cuestión de competencia», Fallos de la Corte Suprema de Justicia, I, 1865, pp. 485-498. 
y exportación de las aduanas, se comprende fácilmente la buena fe con que ha procedido la Legislatura de la Provincia de San Luis, procurando, con la imposición de las contribuciones que contiene la cita ley, crearse recursos con que poder subvenir a las necesidades de su gobierno propio, debiendo suponerse que el producto de esas contribuciones ha sido invertido en los gastos del servicio público y en garantías de seguridad a favor de los bienes y de las personas establecidas en aquella Provincia» ${ }^{14}$.

Este segundo fallo contó con la firma de Bernardo de Irigoyen, como conjuez, en reemplazo de Francisco Delgado, por enfermedad. Irigoyen tendría una actuación más relevante en la discusión del tema, al sostener una breve pero sustanciosa polémica con Marcelino Ugarte sobre la cuestión debatida ante la Corte.

\section{LA POLÉMICA ENTRE MARCELINO UGARTE Y BERNARDO DE IRIGOYEN POR EL CASO «MENDOZA»}

Como sabemos, tanto Ugarte como Irigoyen fueron figuras destacadas en el campo de la justicia y de la política durante el período: Ugarte ocupó brevemente el Ministerio de Relaciones Exteriores durante la presidencia de Mitre, y luego coronó su trayectoria en el mundo del derecho como Ministro de la Corte Suprema desde 1870 hasta su muerte en 1872 .

Bernardo de Irigoyen tuvo una carrera más exitosa en la política, Ministro de Relaciones Exteriores y también Ministro del Interior durante las presidencias de Avellaneda y Roca, su trayectoria política cobraría más brillo aún como figura central del radicalismo. Dos veces senador nacional y gobernador de la provincia de Buenos Aires durante la década del noventa, y figura clave en la política bonaerense hasta su muerte en 1906, Irigoyen fue también un destacado jurista, como lo revela su participación como conjuez de la Corte Suprema en el caso «Mendoza».

Tras el fallo citado, tanto Ugarte como Irigoyen cruzaron sus argumentos en la prensa y sus artículos fueron luego compilados como sendos libros ${ }^{15}$. Los dos

${ }^{14}$ Causa CXXXV, en Fallos de la Corte Suprema de Justicia, III, 1867, fallo del 5 de diciembre de 1865, pp. 131-138.

${ }^{15}$ Marcelino Ugarte, Provincias ante la Corte. Estudio de Derecho Constitucional, Buenos Aires, Imprenta Buenos Aires, 1866; Bernardo de Irigoyen, Justicia Nacional [1866], Buenos Aires, Imprenta Europea de M. A. Rosas, 1903. 
textos reflejan una parecida estrategia argumentativa: a la par de los fundamentos estrictamente constitucionales, combinando antecedentes nacionales y análisis de la jurisprudencia norteamericana, se despliegan interpretaciones propias, y divergentes, del régimen federal argentino, de sus orígenes, y de la manera en la que éste debía regular las relaciones entre gobierno nacional y gobiernos provinciales.

En lo que hace a los argumentos estrictamente constitucionales, Marcelino Ugarte, que había representado a la provincia de Entre Ríos en un proceso similar, presentaba los mismos argumentos que la defensa de San Luis había presentado en el caso «Mendoza»: la Argentina adoptó de la Constitución de los Estados Unidos el espíritu de la jurisprudencia norteamericana que desde antes de la Enmienda XI negaba competencia a las cortes federales para entender en causas iniciadas por particulares contra los estados ${ }^{16}$. Citando a Alexander Hamilton, George Mason, James Madison, y John Marshall en su apoyo, Ugarte señalaba que el sentido de la cláusula constitucional norteamericana era permitir a un estado (o provincia) demandar a un ciudadano de otro estado (o provincia) por el cobro de deudas, y esto debía hacerse ante la Corte federal, pero de ningún modo era aceptado el caso contrario. La Enmienda XI no había sido, según Ugarte, una modificación de los principios constitucionales sino una aclaratoria o explicación de los mismos, necesaria por la posible confusión que el fallo de la Corte norteamericana en Chisolm v. Georgia había generado. Por lo tanto era lógico que la jurisprudencia argentina siguiera la misma línea de denegatoria de la competencia federal ${ }^{17}$. Si bien es cierto que la Ley 48 de organización y competencia de la justicia federal había sido sancionada entendiendo la cláusula constitucional de modo de atribuir jurisdicción a la Corte, Ugarte sostenía que lo que importaba era si esa acepción dada por el Congreso era la correcta o en realidad era opuesta al verdadero sentido de la Constitución, introduciendo una cita de Gorostiaga sobre la preeminencia del texto constitucional sobre la legislación sancionada por el Congreso: «La Constitución es la obra o la expresión de la voluntad del Pueblo mismo, en su capacidad ilimitada, originaria y soberana. La ley es la obra o la expresión de la voluntad del Congreso, en su capacidad derivativa y subordinada».

Como era de esperarse, los argumentos de Bernardo de Irigoyen iban en la dirección opuesta. No hubo nunca una voz que se alzara ni en las convenciones constitu-

16 Marcelino Ugarte, Provincias ante la Corte, op. cit., p. 23.

17 Ídem, pp. 44-45. 
cionales, ni en las cámaras del Congreso al sancionarse las leyes de organización de la justicia federal, que hiciera mención de la necesidad de suprimir la cláusula que sujetaba las causas en las que las Provincias eran demandadas a la jurisdicción de la Corte. La Enmienda XI, que no era una explicación de la Constitución norteamericana sino una modificación de la misma, nunca fue considerada ni siquiera en la convención de reformas de 1859-60, que presuntamente había buscado ampliar la autonomía provincial: «es lógico entonces deducir que si no aceptaron esa enmienda en el texto de la constitución, tomado en gran parte de la constitución americana, fue porque no la creyeron conveniente a los intereses de la nación» ${ }^{18}$.

Las divergencias se volvían más profundas aun cuando ambos autores exponían sus interpretaciones sobre los orígenes del régimen federal argentino y su concordancia o diferenciación respecto del modelo norteamericano, o cuando exponían argumentos de tipo político-institucional que iban más allá de las opiniones estrictamente jurídicas. Marcelino Ugarte presentaba básicamente tres argumentos de este tipo. Con el primero, Ugarte llamaba la atención hacia lo que consideraba un fuerte avance de un «espíritu latente de centralización» en la Argentina. El caso «Mendoza» era un ejemplo de «jurisprudencia unitaria aplicada a una Constitución federal», pero su significación se veía agravada por la acumulación de otros episodios igualmente reveladores de esa tendencia, entre otros, el proyecto de federalización de la provincia de Buenos Aires; el entredicho de 1863 entre el Ministro del Interior Guillermo Rawson y Domingo Faustino Sarmiento, gobernador de la provincia de San Juan en cuanto a la negación a las provincias de la facultad de establecer el estado de sitio $^{19}$; y los proyectos para dar al Congreso Nacional la facultad de fijar derechos de exportación. Sobre este último punto, Ugarte desarrollaba una muy aguda discusión sobre los efectos

\footnotetext{
${ }^{18}$ Bernardo de Irigoyen, Justicia Nacional, op. cit., pp. 95 y siguientes.

${ }^{19}$ En 1863, desempeñándose como gobernador de San Juan, Sarmiento decretó, con autorización de la legislatura provincial, el estado de sitio en su provincia con ocasión de la guerra de las montoneras. El gobierno nacional, a través del ministro del Interior Guillermo Rawson, recordó a los gobernadores que la declaración del estado de sitio era una atribución del Congreso nacional, en algunos casos del Presidente, «pero en ningún caso puede un gobierno de provincia ejercer la referida atribución». Sarmiento respondió recordando que sólo se había delegado al Gobierno Federal el poder de proveer a su propia seguridad y al ejercicio de la Constitución, pero «como los gobiernos provinciales no son autoridades creadas por la Constitución, quedó en ellos retenida la facultad de todo gobierno para precaverse contra la insurrección o la invasión».
} 
que la centralización del régimen fiscal tendría sobre la centralización política y administrativa en general. «Acumúlese entre nosotros facultades al Poder Nacional, suprimiéndolas al poder de las Provincias, y nuestras instituciones se volverán unitarias, aunque las sigamos llamando federales», concluía Ugarte alarmándose por ese avance constante hacia la centralización ${ }^{20}$.

El segundo argumento de Ugarte apuntaba a invalidar el conocido reclamo de quienes negaban la concordancia del régimen constitucional argentino con el norteamericano, alegando la diversidad de orígenes históricos (uno, yendo de la fragmentación hacia la unidad; el otro, yendo de la unidad hacia el reconocimiento de las autonomías locales). Incluso si se quería aceptar la corrección de ese análisis, sugería Ugarte, las conclusiones eran las opuestas a las que llegaban sus defensores:

«Si los Estados Unidos, partiendo de la separación, han acabado por establecer la unión del vínculo federativo, ellos, aleccionados por los inconvenientes de la separación, por la debilidad que provenía de la casi absoluta independencia de los Estados, deben mirar la intimidad de la unión como el ideal político a que les conviene aspirar. Nosotros que, por el contrario, partiendo de la unidad, hemos llegado a la federación, aleccionados por los inconvenientes de la completa unidad, debemos mirar la restricción del Poder general y la dilatación de los Poderes locales, como el ideal político a que nos conviene aspirar ${ }^{21}$.

Finalmente, Ugarte planteaba una fuerte vinculación entre la defensa del «verdadero federalismo" y la libertad individual. Los gobiernos, sostenía, «no necesitan de más fuerza que la que corresponde al desempeño de la misión para la que son instituidos, es decir, al mantenimiento del orden en el seno de la sociedad». Los derechos individuales, cuya protección correspondía al gobierno, podían equipararse a los derechos de «los cuerpos morales que se forman por la agregación de muchos hombres». De ese modo, municipios y provincias tenían, como los individuos, el derecho a emplear sus propios medios del modo que mejor les sirviera a sus propios fines, «sin otro limite que el derecho idéntico de los otros Municipios y de las otras Provincias». Existía, por lo tanto, una muy estrecha vinculación entre la defensa de la soberanía provincial y la autonomía municipal con la defensa de

20 Marcelino Ugarte, Provincias ante la Corte, op. cit., p. 59.

21 Ídem, p. 26. 
la libertad del individuo y de sus derechos, y un ataque a las primeras no podía sino poner en riesgo también a estos otros, creando «un poder único, encargado de tener por todos pensamiento, iniciativa y acción $»^{22}$.

Las interpretaciones de Bernardo de Irigoyen sobre el origen y la evolución del federalismo argentino, nuevamente, eran opuestas a las presentadas por Ugarte. En primer lugar, la distinción entre el "punto de partida» de los Estados Unidos y el de la Argentina era suficiente para invalidar todo intento de «importar» a esta última «las más avanzadas doctrinas de la jurisprudencia americana». Esto constituía el error fundamental de quienes se oponían a la jurisdicción de la Corte: apoyaban sus argumentos en «la imitación estricta del sistema americano», y asimilaban a la Argentina al modelo de una "federación amplia», que establecía una división entre la nación y las provincias «tan profunda como puede existir en las relaciones de una república con un imperio». Citando las críticas de Lucas Alamán y Alexis de Tocqueville, Irigoyen ilustraba el peligro de ese tipo de imitación con los resultados de la constitución mexicana de $1824^{23}$.

En segundo lugar, Irigoyen defendía una concepción de la soberanía nacional que se planteaba como radicalmente distinta a la «soberanía limitada» de las provincias (registrándose aquí una vez más el desplazamiento conceptual hacia una noción de autonomía administrativa ya apuntado), por lo que la objeción a la jurisdicción de la Corte por una supuesta equivalencia entre esas unidades era inválida:

«La identidad que quiere encontrarse en la nación y las provincias no existe. La nación es soberana en la expresión más amplia, mientras las provincias solo invisten una soberanía limitada; esto solo constituye una diferencia sustancial (...) Nuestra organización política nace de la soberanía del pueblo argentino. La personalidad o soberanía interna de las provincias es consecuencia de la soberanía nacional, que desciende a las provincias, no de una manera absoluta, sino de una manera limitada, reducida a lo necesario para la creación de un gobierno propio, de una buena administración interna».

22 Marcelino Ugarte, Provincias ante la Corte, op. cit., p. 15.

${ }^{23}$ Bernardo de Irigoyen, Justicia Nacional, op. cit., pp. 13-14, 27. Las diferencias con los Estados Unidos se extendían no sólo al punto de partida de las dos naciones. Citando a Mármol, Irigoyen recordaba: «hay que tener presente una cosa, y es que aunque nuestras instituciones son modeladas en las de los Estados Unidos, los hombres que las ejecutan no son modelados allí (...) Yo siempre me he hecho esta reflexión cuando he visto esta imitación servil de todo lo que se relaciona con los Estados Unidos: nosotros imitamos las leyes federales, pero no imitamos los hombres federales». Ídem, p. 181. 
Esta distinción era perfectamente compatible con el régimen federal, ya que para Irigoyen (siguiendo en esto a Alberdi) «la federación permite las más variadas combinaciones, fortaleciendo el poder central o debilitándolo, según lo reclamen los precedentes, los intereses y las condiciones del país» ${ }^{24}$. En términos prácticos, además de esa diferencia conceptual, la Corte ya había establecido un principio fundamental: «entre la nación y las provincias existe la diferencia capital de poderse ejecutar a éstas y no a aquella $»^{25}$.

Por último, mientras que Ugarte advertía sobre las negativas consecuencias que la centralización podía traer en términos de concentración del poder y restricción de las libertades, Irigoyen reforzaba sus argumentos centralizadores presentando una lectura muy negativa de los efectos que el principio de las «soberanías provinciales» había tenido en la organización institucional del país:

«la soberanía de las provincias, del modo como quiere entenderse, es un argumento que despierta recuerdos ingratos: a la sombra de esa soberanía mal entendida, los pueblos se envolvieron treinta años en luchas sangrientas: a la sombra de la soberanía provincial, desaparecieron las garantías de la vida y de la propiedad, se levantaron los derechos y las tarifas de tránsito que arruinaron el comercio nacional, se despoblaron las fronteras y se cometieron todos los avances que produjeron por último resultado el despotismo y la anarquía. Esos recuerdos se despiertan con la soberanía provincial mal entendida ${ }^{26}$.

Para Irigoyen, si existía una tendencia hacia una mayor centralización en las instituciones federales, la misma era el resultado de las necesidades del momento, dada la evolución histórica argentina: «la República aún no ha entrado completa-

${ }^{24}$ Bernardo de Irigoyen, Justicia Nacional, op. cit., pp. 112, 131, 167.

${ }^{25}$ La referencia es al fallo de la Corte Suprema de Justicia en Fallos CSJ, II (1865-1866), Causa LXXVII, «El Dr. D. Juan Carlos Gómez, en representación de su hermano D. José Cándido, en demanda contra la Nación», p. 36. El antecedente de este principio estaba dado por la Corte Suprema de los Estados Unidos en Chisolm v. Georgia: «En todos los casos de acciones contra estados o individuos particulares, las cortes nacionales son sostenidas en sus procedimientos y sentencias legales y constitucionales por el brazo del poder ejecutivo de los Estados Unidos. Pero en los casos de acciones contra los Estados Unidos, no hay poder que las cortes puedan llamar en su auxilio: de esta distinción se deducen consecuencias importantes, que colocan el caso de un estado, y el de los Estados Unidos en un punto de vista muy diferente».

${ }^{26}$ Bernardo de Irigoyen, Justicia Nacional, op. cit., pp. 128-130. 
mente en el camino del orden y sus provincias no han convalecido de los cincuenta años de agitación y de guerra, en cuyos fuegos han consumido preciosos elementos de organización y de engrandecimiento».

En ese contexto, era indispensable consolidar el régimen constitucional a través de la utilización de recursos ante la Corte, ampliando la jurisdicción federal en las provincias en todo cuanto fuera posible (Irigoyen veía esta utilización de los recursos ante la Corte como «un resorte indispensable para mantener ilesa la máquina constitucional»). Quienes se oponían a esa expansión de la jurisdicción de la Corte federal parecían no registrar que lo contrario significaba dejar librado a la voluntad de los gobernadores provinciales la subsistencia del régimen constitucional que necesitaba ser afianzado ${ }^{27}$.

Esta perspectiva "centralizadora» que sostenía la ampliación de la jurisdicción federal en las provincias, recibiría nuevo impulso en las décadas siguientes. Dos episodios en particular merecen ser señalados: un fallo de la Corte que en 1874 reafirmaría esa perspectiva, y las nuevas demandas que por una mayor centralización y ampliación de la jurisdicción federal se harían desde el cambio de siglo y hacia finales del roquismo.

\section{LAS DERIVACIONES DEL DEBATE \\ Y LA JURISPRUDENCIA DE LA CORTE: EL CASO «AVEGNO» (1874)}

Si bien el fallo de la Corte en «Mendoza» parecía consagrar la interpretación «centralizadora» defendida por Irigoyen, la cuestión volvería a plantearse en la década siguiente. En abril de 1874 la Corte Suprema dictó sentencia en un caso que permitió una nueva confirmación de los principios que se habían asentado en el caso anterior (tres de los cinco jueces firmantes en esta oportunidad habían firmado el caso anterior: Salvador María del Carril, Francisco Delgado, y José Barros Pazos. Se sumaron en este nuevo fallo José Benjamín Gorostiaga y José Domínguez ${ }^{28}$. El ciudadano uruguayo José Avegno solicitó reivindicar una

${ }^{27}$ Bernardo de Irigoyen, Justicia Nacional, op. cit., p. 183.

${ }^{28}$ Fallos CSJ, XIV (1873-1874), Causa XXI, «Don José Leonardo Avegno contra la Provincia de Buenos Aires, sobre reivindicación de una finca», pp. 425-449. Marcelino Ugarte, que había sido designado ministro de la Corte en 1870 había fallecido en 1872, dos años antes del caso «Avegno». Cabe preguntarse si su presencia en la Corte hubiera atenuado, tal vez a través de un voto en disidencia, el consenso tan favorable a la confirmación de la jurisdicción federal. 
propiedad que el gobierno de la provincia de Buenos Aires había comprado de un concurso de acreedores de Avegno unos ańos antes. Habiendo denegado el gobierno de la provincia las solicitudes de Avegno, éste se presentó ante la Corte Suprema entablando esa acción reivindicatoria. Cuando la Corte dio traslado al fiscal general de la provincia de Buenos Aires, el mismo rechazó la jurisdicción de la Corte, presentando argumentos similares a los que la provincia de San Luis había aducido casi una década antes: en primer lugar, «los gobiernos provinciales son independientes y soberanos y obligar a una provincia a comparecer ante la barra del tribunal federal en una demanda de un particular era desconocer su independencia y soberanía». Por otra parte, la Enmienda XI de la constitución norteamericana no era una cláusula nueva, sino una aclaración de los principios de esa constitución, que negaban la jurisdicción de las cortes federales. Por último, no podía alegarse la teoría de la diferencia de origen de ambos países (el argumento de Bernardo de Irigoyen), "por ser nuestro ideal político la emancipación de los poderes locales».

La defensa de Avegno, en cambio, insistió, entre varios argumentos, en que los constituyentes argentinos nunca habían considerado incorporar la enmienda norteamericana a los artículos 100 y 101 de la Constitución, argumento que fue apoyado por el Procurador General, quien insistió, además, que antes de la Enmienda XI se reconocía en la Corte federal de los Estados Unidos jurisdicción para conocer en las demandas de los particulares contra las provincias.

El fallo de la Corte argentina, apoyándose en el precedente del caso «Mendoza», ampliaría los argumentos en favor de la jurisdicción federal, sosteniendo además que la misma en modo alguno implicaba un menoscabo de la dignidad o de la «soberanía de las provincias», o un obstáculo para la administración interna de las mismas.

Toda la argumentación que defendían quienes negaban la jurisdicción federal caía cuando se comprobaba que en el modelo norteamericano esa negativa sólo había aparecido con la Enmienda XI a la constitución, no antes, y que la misma era efectivamente una enmienda, y no una aclaración: «resulta por consiguiente, que habiendo adoptado nuestra Constitución el texto originario de la Americana, omitiendo la enmienda XI que lo modificó, es evidente que quiso dar a la jurisdicción de este Tribunal la extensión que tenía el Americano según aquel texto, sin la limitación de la enmienda omitida». Ni en 1853 ni en 1860 habían aparecido indicios de que se quisiera limitar la jurisdicción federal, y tampoco había habido iniciativa alguna en ese sentido en el Congreso. Como otro antecedente relevante, el fallo recordaba que «el hábil abogado que dirigía en juicio a una de las Provincias 
resistentes» (la provincia era Entre Ríos, y su representante, Marcelino Ugarte) había promovido una reforma de la Constitución para producir una enmienda similar a la norteamericana, y el Congreso había rechazado tal iniciativa "casi por unanimidad».

Finalmente el fallo de la Corte reafirmaba el principio de limitación al ejercicio de «una soberanía absoluta» de parte de las provincias. Estas limitaciones no sólo estaban legítimamente contempladas en el ordenamiento constitucional sino que eran además necesarias para el eficaz funcionamiento del mismo, y las mismas provincias las habían consentido «por altas consideraciones de política y de interés común», entre otras, el asegurar el ejercicio de «una justicia libre de toda sospecha de parcialidad»:

«El Gobierno de las Provincias ha continuado libremente ejercido por los poderes constituidos de cada una de ellas; el régimen federal ha permanecido ileso; ninguno de los peligros señalados se ha convertido en hecho efectivo, y el único resultado que puede mostrarse del ejercicio de la jurisdicción de la Corte, es el de haberse evitado una violación de la Constitución que sin ella se habría consumado» ${ }^{29}$.

En definitiva, la Corte Suprema, tanto en 1865 como en 1874, confirmó la jurisdicción federal en las causas iniciadas por particulares contra las provincias basándose tanto en el plano de los argumentos de derecho constitucional (artículos respectivos de la constitución nacional, ley 48 de organización de la justicia federal, antecedentes norteamericanos) como en una interpretación "centralizadora» del federalismo argentino, según la cual los tribunales federales se erigían como una instancia garantizadora del cumplimiento del orden constitucional en un contexto de alta desconfianza de la capacidad de las instituciones provinciales locales para llevar adelante esa tarea.

Si, como bien se ha señalado, la llegada de Nicolás Avellaneda a la presidencia ese mismo año simbolizó la consolidación de un sistema político en el que las provincias se integraban "no sometiéndose a un centro sino constituyéndolo", por el cual las mismas elites políticas provinciales fueron estableciendo acuerdos e instituciones convenidas por los poderes locales y los representantes del poder

29 ĺdem, p. 446. 
central $^{30}$, también es cierto que ese proceso político de consolidación del estado nacional generó como resultado un constante proceso de absorción por las instituciones federales de atributos y prerrogativas que las provincias habían ejercido o podían aspirar a ejercer, según una visión alternativa del régimen federal ${ }^{31}$.

A partir de 1880 y el afianzamiento del régimen roquista, ese tenso equilibrio entre la participación en el sistema político de las elites provinciales y la construcción institucional que mantenía esas fuertes tendencias centralizadoras, se prolongaría, acentuando algunos de sus rasgos ${ }^{32}$. Lejos de llegarse a una pacífica consolidación del sistema, en el cambio de siglo -y en parte alimentados por las nuevas inquietudes reformistas-, se alzarían nuevos reclamos sobre el mal funcionamiento del sistema federal argentino y nuevas demandas por mayores medidas de centralización, en particular por una nueva ampliación de la jurisdicción de los tribunales federales.

\section{JUSTICIA FEDERAL Y SOBERANÍAS PROVINCIALES EN EL CAMBIO DE SIGLO}

En 1902 José Nicolás Matienzo publicó una nota periodística en El Diario que bajo el título «La reforma judicial» discutía la ley de reorganización de la justicia federal sancionada en enero de ese año. Matienzo reelaboraría los argumentos allí desarrollados con más detalle una década más tarde en «Ampliación de la Justicia Federal», publicado en la Revista Argentina de Ciencias Politicas, y en su libro El gobierno representativo federal en la República Argentina ${ }^{33}$. Matienzo

${ }^{30}$ Beatriz Bragoni y Eduardo Míguez, «De la periferia al centro: la formación de un sistema político nacional, 1852-1880", en: Bragoni y Míguez, Un nuevo orden político, op. cit., p. 27.

${ }^{31}$ Chiaramonte y Buchbinder, «Provincias, caudillos, nación», op. cit., p. 94.

32 Véase para distintas perspectivas sobre ese proceso, Natalio Botana, El orden conservador. La política argentina entre 1880 y 1916, Buenos Aires, Editorial Sudamericana, 1977; Paula Alonso, Jardines secretos, legitimaciones públicas. El Partido Autonomista Nacional y la política argentina de fines del sig/o XIX. Buenos Aires, Edhasa, 2010; Pablo Gerchunoff, Fernando Rocchi y Gastón Rossi, Desorden y progreso. Las crisis económicas argentinas, 1870-1905, Buenos Aires, Edhasa, 2008; Martín O. Castro, El ocaso de la república oligárquica. Poder, política y reforma electoral, 1898-1912, Buenos Aires, Edhasa, 2012.

33 José Nicolás Matienzo, «Ampliación de la Justicia Federal», Revista Argentina de Ciencias Políticas, vol. IV, 1912; José Nicolás Matienzo, El gobierno representativo federal en la República Argentina, Buenos Aires, Coni Hermanos, 1910. 
ilustraba ampliamente la centralidad que los problemas del régimen federal, y en particular los problemas de la justicia federal, tenían en el funcionamiento del sistema político argentino, en una línea de pensamiento que exhibía fuertes continuidades con lo expuesto por Alberdi y Bernardo de Irigoyen casi medio siglo antes. La reforma constitucional de 1860 había deformado trágicamente el sistema diseñado según el texto de 1853, introduciendo bajo la inspiración de un fuerte «espíritu provincialista» una serie de restricciones y trabas a las facultades de los poderes nacionales que, en particular, habían debilitado a la justicia federal y acrecentado las jurisdicciones provinciales (proceso agravado por un número de leyes sancionadas por el congreso en el mismo sentido en los años siguientes a la reforma constitucional). Por la reforma de 1860 el congreso nacional había sido privado de la facultad de examinar las constituciones provinciales para asegurar la administración de justicia y el cumplimiento de las garantías federales de funcionamiento de las instituciones locales de acuerdo con la constitución nacional, y se había quitado a la cámara de diputados el derecho de acusar ante el senado a los gobernadores de provincia. Estas modificaciones habían otorgado a los gobiernos de provincia un margen mayor de maniobra sobre los sistemas judiciales, facilitando aún más la concentración de poder en la persona de los gobernadores.

Las leyes orgánicas de la justicia federal de 1863 y 1878 habían restringido aún más la jurisdicción federal, excluyendo de la competencia de los jueces federales a una gran cantidad de casos. Según Matienzo, la ley de 1902 no había modificado mayormente la situación del poder judicial federal respecto de los provinciales. Pero la evolución del marco legal-institucional era sólo meramente indicativa de los que las prácticas concretas habían producido:

«Todas las referidas limitaciones puestas desde 1860 al ejercicio de la justicia nacional han servido en definitiva para favorecer la arbitrariedad y desamparar el derecho, expuesto a todo género de incertidumbres en presencia de quince administraciones de justicia diferentes, sin que se haya conseguido realizar el régimen federativo de los Estados Unidos, a cuya imposible imitación se han sacrificado los antecedentes y necesidades reales de la República Argentina».

Los verdaderos resultados jurídicos de la soberanía provincial, nombre que los defensores de la reforma de 1860 daban a lo que para Matienzo no era más que «el poder excesivo confiado al caciquismo local», eran una absurda diversidad de 
interpretaciones locales dadas a los códigos nacionales, una arbitraria variedad de procedimientos, y el facilitar la indebida influencia de los poderes políticos provinciales sobre sus aparatos judiciales: «una larga experiencia ha demostrado que los jueces de provincia hacen lo posible para no fallar contra su gobierno, o mejor dicho, contra los deseos del gobernador, salvo escasas y honrosas excepciones».

Las soluciones residían en una reforma constitucional que eliminara las cláusulas introducidas en 1860 y en la derogación de las leyes del congreso que habían transferido a los jueces locales atribuciones de carácter federal. $Y$ en lo que hacía al desarrollo de la jurisprudencia, concluía Matienzo, «convendría que la ley le diera rumbos más nacionalistas, estableciendo el principio general de que, en caso de duda, las cuestiones de competencia entre jueces federales y provinciales deban decidirse a favor de los primeros; porque ellos representan la justicia suprema del país».

Al igual que Matienzo, Rodolfo Rivarola también destacó en su análisis crítico del sistema federal argentino a la debilidad del sistema judicial federal como uno de los síntomas del estado crítico del régimen. Si bien los dos autores diferían en cuanto a la eventual solución de la crisis -Rivarola postulando la necesidad de abandonar el experimento federalista y adoptar un sistema unitario de gobierno; Matienzo intentando rescatar una versión más centralizadora del federalismo, acorde con la fórmula original de la Constitución de 1853-, ambos estaban de acuerdo en que el fortalecimiento de la justicia federal era un necesario primer paso ${ }^{34}$.

Tanto los argumentos de Matienzo como Rivarola, como los de las partes en los casos planteados ante la Corte en 1865 y 1874, como gran parte del debate políticoconstitucional de la segunda mitad del siglo diecinueve, en definitiva, ponían el acento en el clivaje «soberanía nacional/soberanías provinciales» como clave para entender lo que se consideraban peligros o amenazas para la consolidación del régimen político. $\mathrm{O}$ mucha centralización o muy poca centralización parecían ser las fórmulas en la que se resumían las posiciones en conflicto. La centralidad de ese tópico sugiere que otras posibles maneras de acercarse a la discusión de los fundamentos de ese régimen parecían postergadas o subordinadas ante la fuerza que esos dos polos conceptuales ejercían en el debate público argentino.

${ }^{34}$ Rodolfo Rivarola, Del régimen federativo al unitario, Buenos Aires: Peuser, 1908, Cap. XIII, pp. 227240, «El federalismo no ha afianzado la justicia»; José Nicolás Matienzo, El gobierno representativo federal en la República Argentina, Madrid: Editorial América, $2^{\circ}$ edición, 1917 ( $1^{\circ}$ edición, Buenos Aires, 1910), Cap. XVI, pp. 293-303, «La justicia en la Argentina». 


\section{«PODERES» $Y$ «DERECHOS»: LA DISCUSIÓN}

\section{POR EL FEDERALISMO Y EL LIBERALISMO EN LA ARGENTINA DEL SIGLO XIX}

El historiador norteamericano Morton Keller planteó hace algún tiempo un sugerente modelo interpretativo sobre la evolución histórica del constitucionalismo norteamericano que puede servir para ilustrar esa característica del debate constitucional argentino del siglo diecinueve. Keller sugirió que en los Estados Unidos, esa evolución podía entenderse en términos del despliegue de dos grandes temas, cronológicamente consecutivos. El primero de esos temas, preponderante desde los orígenes de la nueva república hasta fines del período de la reconstrucción posterior a la Guerra Civil, fue el de la distribución de poderes, esto es, la extensión de la autoridad de cada rama y nivel de los gobiernos en sus relaciones mutuas, en particular las conflictivas relaciones entre los gobiernos estaduales y el gobierno nacional. Esto, según Keller, no era más que el reflejo del constante juego entre centros y periferias que se dio en todos los procesos de construcción de los estados nacionales modernos.

El segundo gran tema en la historia del constitucionalismo norteamericano surgió, según Keller, de una conjunción de problemas vinculados al establecimiento de los derechos de individuos y de grupos, y tendió a reflejar las transformaciones económicas y sociales que los Estados Unidos atravesaron desde fines del siglo diecinueve. La trayectoria cubrió un arco que iba de un constitucionalismo dominado por los debates sobre la distribución de poderes entre centro y periferia, a un constitucionalismo orientado a la discusión de la extensión de derechos y su ejercicio por grupos excluidos. Del énfasis puesto en la discusión del carácter y extensión de la soberanía nacional encarnada en el gobierno federal, al énfasis en el carácter y extensión de los derechos de la ciudadanía, y en particular de los derechos y del ejercicio de la ciudadanía de la población de color, que había sido excluida como sujeto de esos debates durante décadas. La Guerra Civil en los Estados Unidos en cierto modo simbolizó el entrecruzamiento de esos dos grandes temas y la transición de uno hacia el otro: las divergentes interpretaciones sobre las soberanías estaduales frente a la Unión, y la consagración de una nueva manera de extender los derechos individuales a través de la Emancipación proclamada por Lincoln y las luchas consiguientes por hacer efectivas esas reivindicaciones, que se extenderían por un siglo más ${ }^{35}$.

${ }^{35}$ Morton Keller, «Powers and Rights: Two Centuries of American Constitutionalism», The Journal of American History, vol. 74, n³, Dec. 1987, pp. 675-694. 
En la Argentina de la Organización Nacional, como sugerí al comienzo de este trabajo, la preponderancia de la discusión por la distribución de poderes o facultades entre el gobierno nacional y los gobiernos provinciales fue tal que tendió a obstruir la posibilidad de otras perspectivas críticas del proceso de construcción del estado nacional. Tomemos como ejemplo una temprana discusión por la facultad del Poder Judicial de interpretar la Constitución y la concordancia de las leyes y los actos del Poder Ejecutivo con la misma -el llamado control de constitucionalidad. Tanto los cuerpos legislativos de la Confederación como del estado de Buenos Aires coincidieron en sendos debates en 1858 en adoptar la doctrina de la interpretación judicial de la Constitución. Sin embargo, no faltaron en estos debates opiniones contrarias al otorgamiento de esa facultad a la justicia federal. En particular, el diputado Vicente G. Quesada rechazaba en el Congreso de Paraná «la necesidad de que se constituyese el Poder Judicial, con un carácter enteramente central y unitario desnaturalizando el principio federal, porque esto sería establecer el Consejo de Indias con el título de Corte Suprema de Justicia Federal, con omnímodas facultades y sin contrapeso ni equilibrio en los otros poderes ${ }^{36}$. Resulta llamativo que el argumento utilizado por Quesada para atacar el principio de control de constitucionalidad, si bien mencionaba la necesidad del equilibrio entre los poderes, se centraba sobre todo en el carácter «enteramente central y unitario» del Poder Judicial. Es decir la distribución de poderes entre instituciones federales e instituciones provinciales primaba sobre una discusión en torno a la legitimidad del control de constitucionalidad como elemento de protección de derechos individuales capaz de invalidar actos de los poderes elegidos democráticamente (la llamada «dificultad contramayoritaria» ${ }^{37}$ ).

\footnotetext{
${ }^{36}$ Abelardo Levaggi, "La interpretación del derecho en la Argentina en el siglo XIX», Revista de Historia del Derecho, vol. 7, 1980, pp. 23-32; Dardo Pérez Guilhou, «Primer debate sobre el control jurisdiccional de constitucionalidad (1857-1858)», Revista de Historia del Derecho, vol. 10, 1983, pp. 147-170; Jonathan M. Miller, «The Constitutional Authority of a Foreign Talisman: A Study of U.S. Practice as Authority in 19th Century Argentina and the Argentine Elite's Leap of Faith", The American University Law Review vol. 46, n 5, June 1997.

${ }^{37}$ Para las discusiones sobre la «dificultad contramayoritaria» en los Estados Unidos, véase Alexander Bickel, The Least Dangerous Branch. The Supreme Court at the Bar of Politics, New Haven: Yale University Press, 1962; William E. Nelson, «Changing Conceptions of Judicial Review: The Evolution of Constitutional Theory in the States, 1790-1860", University of Pennsy/vania Law Review, vol. 120, $n^{\circ}$ 6, 1972; Larry D. Kramer, The People Themselves. Popular Constitutionalism and Judicial Review, Oxford, Oxford University Press, 2004.
} 
Cuando la Corte Suprema argentina finalmente introdujera ese principio de control hacia fines de la década del ochenta en el caso «Sojo», el mismo sería el resultado del seguimiento casi instintivo que la corte argentina hacía de la jurisprudencia norteamericana más que del contexto local ${ }^{38}$.

La comparación también es relevante con la evolución del pensamiento liberal europeo. Como bien ha señalado Darío Roldán, la constitución de la tradición liberal tras la ruptura conceptual que produjo la Revolución Francesa, se centra en «la crítica a la idea democrática», de la que surgirá luego una nueva síntesis política. En el caso argentino, observa Roldán, la ausencia de una crítica articulada a la noción de soberanía desde la defensa de los derechos individuales, signada por el fuerte impacto en el siglo XIX de «formas románticas que anteponían la cuestión de la nación a la reflexión individualista», fue uno de los elementos que dio forma a la particular versión del liberalismo forjada en la Argentina del siglo diecinueve. Un liberalismo que terminaría enfrentando el problema de construir un «liberalismo de gobierno» sin haber pasado por una etapa de liberalismo de oposición, y que daría forma a esos dos rasgos tan salientes de la tradición liberal argentina decimonónica: la primacía de la preocupación por el orden por sobre la de la libertad, y las preferencias por fórmulas centralizadoras de la autoridad ${ }^{39}$.

La cuestión de la nación, entonces, y su traducción en las querellas entre centralización y descentralización ${ }^{40}$, tendió a ocupar el espacio conceptual que en otras tradiciones giró más bien en torno a la polarización soberanía democrática/derechos individuales. Por supuesto que esto no sugiere que no hubo en la Argentina del siglo diecinueve intentos por conciliar las dos dimensiones de esos debates. Se mencionó ya aquí el intento de Marcelino Ugarte de basar su defensa de las

${ }^{38}$ Véase Jonathan M. Miller, «The Constitutional Authority of a Foreign Talisman», op. cit., y su análisis de los orígenes del «control de constitucionalidad» o judicial review en la Argentina como otra cara del entusiasmo de la dirigencia política del período con el modelo institucional norteamericano.

${ }^{39}$ Darío Roldán, «La cuestión liberal en la Argentina en el siglo XIX. Política, sociedad, representación», en: Beatriz Bragoni y Eduardo Míguez (coord.), Un nuevo orden político. Provincias y estado nacional 1852-1880, Buenos Aires, Editorial Biblos, 2010, pp. 275-291.

40 «La querella entre federalistas y centralistas... no sólo ponía en juego el reparto del poder entre las elites regionales sino algo más profundo todavía: la manera de concebir y representar la nación», sugirió F. X. Guerra en "Las metamorfosis de la representación en el siglo XIX», en: Georges Couffignal (comp.) Democracias posibles. El desafío latinoamericano, México, Fondo de Cultura Económica, 1994. 
soberanías provinciales en su conceptualización de las mismas como extensiones de las libertades individuales. Unos ańos antes, en 1860, cuando Buenos Aires examinaba las propuestas de reforma de la constitución de 1853, el Informe de la comisión examinadora (redactado por Mitre, acompañado por Sarmiento y Vélez Sarsfield) presentaba las reformas apoyándose en una interpretación histórica de las raíces locales del federalismo. El texto desgranaba la evolución constitucional argentina como una serie de intentos fracasados que habían dejado como saldo a la nacionalidad argentina como un hecho, más que como una situación de derecho. De este proceso, sin embargo, surgían al menos dos principios fundamentales, «las soberanías provinciales, como base de toda organización nacional, y la libertad, fin a que debe subordinarse toda organización política». Estos dos principios, el federalismo y el liberalismo, se habían manifestado en dos acontecimientos concretos de la historia argentina: la sanción de la Constitución federal de 1853, y la revolución porteña del 11 de Septiembre de 1852, respectivamente. Mitre retomaba así su identificación de la causa porteña desde 1852 con la causa de la libertad ${ }^{41}$, que debía ahora complementarse con la realidad del federalismo encarnado en las soberanías provinciales. La unión de estos dos principios, equivalente a la unión de las dos fracciones que se habían enfrentado en el país, era el paso necesario que debía darse a través de la reforma constitucional para garantizar la organización definitiva de la Nación: «fuertes ambos, dotados de esa vitalidad que caracteriza a los principios conservadores de las sociedades humanas, su amalgama es lo único que puede dar estabilidad a la Constitución.... ${ }^{42}$.

Alberdi, en cambio, siempre desconfió de esa vinculación entre descentralización política y defensa de las libertades individuales, y en uno de sus textos póstumos sintetizó su oposición a esa identificación, a la que veía como cierta en los Estados Unidos, pero no en la América española:

${ }^{41}$ Tulio Halperin Donghi, «Una nación para el desierto argentino», en: Proyecto y Construcción de una Nación (Argentina 1846-1880), Caracas, Biblioteca Ayacucho, 1980, p. XIVII.

42 Emilio Ravignani, Asambleas Constituyentes Argentinas, vol. IV, pp. 767-68 (subrayado agregado). En esta obra de Emilio Ravignani están reproducidas las sesiones de la Convención del Estado de Buenos Aires (pp. 705-948), seguidas por las sesiones de la Comisión Examinadora de la Constitución que se publicaban como El Redactor de la Comisión Examinadora de la Constitución Federal (pp. 949-988). 
«Hay localismo y localismo; el localismo sajón, que significa la iniciativa individual, y el localismo latino, que no significa sino la suma o perturbación de la iniciativa central (...) No hay que pensar que la iniciativa individual se establece y resulta del simple hecho del desquicio de la iniciativa pública o colectiva del Estado. No hay que ver una federación por el estilo de la de Estados Unidos en toda República de Sud-América en que ha desaparecido la autoridad unitaria o central. Lo que resulta, en este último caso, es la desaparición y ausencia de toda autoridad, tanto individual como central; no es la descentralización; es la anarquía; no es la autoridad distribuida y dividida entre las localidades del país, sino la autoridad que ausente de la nación sin encontrarse en las localidades, acostumbradas a recibirla de una esfera Suprema o Nacional, por siglos, desde su nacimiento; y jamás a darla ${ }^{43}$.

Como hemos visto, esa preferencia por la centralización del poder se iría asentando como el discurso dominante. Para muchos observadores ese proceso contribuyó a debilitar, no sólo en la Argentina sino en toda la tradición constitucional latinoamericana del siglo diecinueve la implantación de una cultura jurídica de derechos y dispositivos institucionales de garantía ${ }^{44}$. Jeremy Adelman señaló que el impulso de construcción de autoridad ejecutiva en el momento constituyente argentino «vació de contenido los compromisos constitucionales que hacían a la defensa de los derechos de los ciudadanos, impidiendo de ese modo la aparición de frenos externos al poder estatal» ${ }^{45}$. Más recientemente, Roberto Gargarella ha apuntado la difícil conciliación que los ideales del autogobierno colectivo y la autonomía individual tendrían en el constitucionalismo latinoamericano con los mecanismos de organización del poder («la sala de máquinas de la Constitución»), y otros han destacado el diseño de los "poderes de emergencia» en los textos

\footnotetext{
${ }^{43}$ Juan Bautista Alberdi, Del gobierno en Sudamérica según las miras de su revolución fundamental (1863, 1867), tomo IV de los Escritos póstumos [1896], Buenos Aires, Universidad Nacional de Quilmes, 2002, también publicado como Juan Bautista Alberdi, La monarquía como mejor forma de gobierno en Sudamérica, estudio preliminar y notas de Juan Pablo Oliver, Buenos Aires, A. Peña Lillo editor, 1970, p. 367.

${ }^{44}$ Carlos Garriga (coor.), Historia y constitución. Trayectos del constitucionalismo hispánico, México, CIDE/Instituto Mora/El Colegio de Michoacán/ELD/HICOES/EI Colegio de México, 2010, pp. 14, 19. 45 Jeremy Adelman, Republic of Capital. Buenos Aires and the Legal Transformation of the Atlantic World, Stanford, Stanford University Press, 1999, p. 222.
} 
constitucionales como dificultades para la consolidación de los nuevos regímenes políticos en la región ${ }^{46}$.

Esas dificultades no imposibilitaron que, en el caso argentino, las instituciones judiciales federales desarrollaran mecanismos de protección de derechos individuales o de control entre poderes, y los mismos deben ser vistos también como una dimensión relevante de la construcción del estado nacional ${ }^{47}$. Sin embargo, tal como queda ilustrado en los casos planteados ante la Corte aquí analizados, y sus repercusiones posteriores en las décadas siguientes, resulta abrumadora en el discurso constitucional del siglo diecinueve la predominancia de las preocupaciones por la distribución de poderes entre el estado nacional y las provincias y el relegamiento de una elaboración conceptual sistemática de los derechos individuales como frenos a la soberanía estatal.

\section{Registro bibliográfico \\ ZIMMERMANN, EDUARDO}

«Soberanía nacional y soberanías provinciales ante la Corte Suprema de Justicia. Argentina, siglo XIX», en: ESTUDIOS SOCIALES, revista universitaria semestral, año XXV, $n^{\circ} 48$, Santa Fe, Argentina, Universidad Nacional del Litoral, primer semestre de 2015, pp. 11-37.
Recibido: 18 / 02 / 2014

Aprobado: 15 / 03 / 2015

${ }^{46}$ Roberto Gargarella, La sala de máquinas de la Constitución. Dos siglos de constitucionalismo en América Latina (1810-2010), Buenos Aires, Katz Editores, 2014; véase también su trabajo anterior Los fundamentos legales de la desigualdad. El constitucionalismo en América (1776-1860), Madrid, Siglo XXI, 2005. José Antonio Aguilar Rivera, En pos de la quimera: reflexiones sobre el experimento constitucional atlántico, (México, Fondo de Cultura Económica/CIDE, 2000, y El manto liberal: Ios poderes de emergencia en México: 1821-1876, México, Instituto de Investigaciones Jurídicas/UNAM, 2001; Brian Loveman, The Constitution of Tyranny: Regimes of Exception in Spanish America, Pittsburgh, University of Pittsburgh Press, 1994.

47 Eduardo Zimmermann, «En tiempos de rebelión. La justicia federal frente a los levantamientos provinciales, 1860-1880», en: Bragoni y Míguez, Un nuevo orden político, op. cit., pp. 245-273. 
